\title{
Prevalence of Knee Osteoarthritis and Health-Related Quality of Life in Stroke Patients over 60 Years Old: A Cross-Sectional Study Using Korean National Health and Nutrition Examination Survey V
}

\author{
Kil-Yong Jeong ${ }^{1}$, Hyun Jung Lee ${ }^{2,3}$ \\ ${ }^{1}$ Department of Physical Medicine and Rehabilitation, Ajou University Hospital, Suwon, Korea \\ ${ }^{2}$ Department of Physical Medicine and Rehabilitation, Jeju National University Hospital, Jeju, Korea \\ ${ }^{3}$ Graduate Program of Medicine, Ajou University Graduate School, Suwon, Korea
}

Corresponding Author:

Hyun Jung Lee, MD

Department of Physical Medicine and

Rehabilitation, Jeju National University

Hospital, Aran 13-gil 15, Jeju 63241,

Korea

E-mail: sigano@hanmail.net

ORCID:

https://orcid.org/0000-0003-0202-587X

Received: May 27, 2021

Revised: June 16, 2021

Accepted: June 18, 2021
Background: This study investigated the prevalence of knee osteoarthritis among stroke survivors aged over 60 years and analyzed the association between knee osteoarthritis and health-related quality of life (HROOL) in stroke survivors. Methods: We analyzed data of 287 participants who had experienced a stroke (stroke group) from the 2010-2012 Korean National Health and Nutrition Examination Survey. Among the participants, 65 stroke survivors also had knee osteoarthritis. We used the European Quality of Life-5 Dimensions (EQ-5D) questionnaire to compare the differences in $\mathrm{HROOL}$ according to the presence or absence of knee osteoarthritis in the stroke group. Multiple regression analysis was performed to determine associated factors affecting HROOL in the stroke group. Results: The prevalence of knee osteoarthritis was 21\% in the stroke group. The EQ-5D index score was significantly lower in patients in the stroke group with knee osteoarthritis than in those without knee osteoarthritis (adjusted mean \pm standard error [SE], $0.680 \pm 0.011$ for stroke with knee osteoarthritis and $0.817 \pm 0.003$ stroke without knee osteoarthritis; $p<0.0001$ ). Knee osteoarthritis, age, income level, education level, smoking, diabetes, and cardiovascular disease significantly influenced HROOL in the stroke group. Conclusion: The study results confirmed that the prevalence of knee osteoarthritis was 21\% in the stroke group and that HRQOL was significantly lower among patients in the stroke group with knee osteoarthritis. These findings suggest the importance of active management of knee osteoarthritis in stroke survivors for $\mathrm{HROOL}$.

Key Words: Nutrition surveys, Osteoarthritis, Prevalence, Quality of life, Stroke

\section{INTRODUCTION}

Stroke can cause physical and mental impairments and is often accompanied by a decline in the quality of life owing to chronic sequelae. $^{1-4)}$ According to an epidemiological report published by the Korean Stroke Society in 2018, one in 40 Korean adults have had a stroke and 232 strokes occur per 100,000 people each year. ${ }^{5}$ With the advancement of medical care, the mortality rate of patients with stroke has decreased over time, ${ }^{6}$ resulting in an increased number of patients living with the disease and its associated disorders.

The disabilities that result from stroke include not only neurological disorders but also decreased physical function. ${ }^{7,8)}$ Musculoskeletal issues are reported in $29 \%-32 \%$ of patients affected by stroke. ${ }^{9)}$ The decline in muscle strength and/or motor control function, in addition to muscle spasticity, can cause limb abnormalities and an irregular gait. These symptoms may result in increased pain and may limit patient activities of daily living. ${ }^{10)}$ 
In particular, osteoarthritis caused by a degenerative joint disorder typically accompanies stroke owing to its increasing prevalence with age. ${ }^{11-13)}$ Osteoarthritis is characterized by chronic joint pain and functional limitations, including gait instability; it also affects mental health, with increased risks of stress and depression. ${ }^{14)}$ Osteoarthritis can also worsen the function of patients with stroke, ${ }^{15,16)}$ negatively impacting their health-related quality of life (HRQOL). ${ }^{17)}$ In addition, stroke survivors often have comorbidities such as hypertension, diabetes, and cardiovascular disease, which can also affect HRQOL. ${ }^{18)}$ Decreased HRQOL is associated with depression, decreased motivation, and social withdrawal. ${ }^{19)}$ These can also lead to the deterioration of other functions, activity, and mobility. Therefore, improving the HRQOL of patients with stroke not only improves their mental outlook but may also lead to functional improvements and increased social participation.

Korea's progression to a super-aged society and the increase in the number of stroke survivors have resulted in increased strokeand osteoarthritis-related research. ${ }^{6,20)}$ Thus, as a representative musculoskeletal disease that can accompany stroke, osteoarthritis is expected to become increasingly important.

However, few studies have assessed the prevalence and effect of knee osteoarthritis on HRQOL in patients with stroke. Therefore, this study investigated the prevalence of knee osteoarthritis among stroke survivors and analyzed the association of knee osteoarthritis and HRQOL in stroke survivors aged over 60 years.

\section{MATERIALS AND METHODS}

\section{Research Design and Participants}

This cross-sectional study analyzed raw data from the 5th Korean National Health and Nutrition Examination Survey (KNHANES) between 2010 and 2011. The 5th KNHANES documented health behavior, prevalence of chronic disease, dietary intake, and results of radiological tests such as knee and hip X-rays to evaluate osteoarthritis.

Among 25,534 respondents in the 5th KNHANES, we selected 287 for the final analysis. The inclusion criteria for the stroke group in this study were as follows: (1) diagnosis of stroke, (2) currently having stroke, or (3) currently undergoing stroke treatment, and (4) age $\geq 60$ years (Fig. 1). This study was approved by the Institutional Review Board of Jeju National University Hospital (No. 2020-05-001). As the present study used non-personally identifiable data, the requirement for participant consent was waived and the study was conducted according to the principles of the Declaration of Helsinki and the International Council for Harmonisation-Good Clinical Practice (ICH-GCP).

\section{Explanatory Variables}

The knee osteoarthritis group comprised individuals who reported having knee pain and knee joint Kellgren-Lawrence radiological grades $\geq 2$. We used the European Quality of Life-5 Dimensions (EQ-5D) questionnaire to compare the differences in HRQOL according to the presence or absence of knee osteoarthritis in the stroke group. EQ-5D comprises five dimensions related to HRQOL: mobility, self-care, daily activities, pain/discomfort, and anxiety/depression. Each domain of EQ-5D is scored using a three-point scale: 1 , no problems; 2 , moderate problems; and 3, severe problems. A higher score indicates greater discomfort in each dimension. The EQ-5D results were then converted into the EQ-5D index according to the EQ-5D measurement standards proposed by the Korea Centers for Disease Control and Prevention. ${ }^{21)}$ An EQ-5D index of 1 (when all five items were 1) defined a perfectly healthy condition. EQ-5D indices ranged from 1 to -0.171 , with smaller values indicating worse health conditions. ${ }^{22)}$

The sociodemographic variables included in our analysis were age (years), age group (60-69, 70-79, and $\geq 80$ years), sex (male, female), income, and education. Income was divided into quartiles (lower, lower-middle, upper-middle, and upper). The levels of education were divided into $\leq$ middle school or $\geq$ high school. We assessed smoking status, alcohol intake per week, and number of walking days as lifestyle factors. Smoking status was divided into currently smoking and non-smoking. Alcohol intake per week was divided into no drinking, $\leq 1$ time/week, 2-3 times a week, and $\geq 4$ times a week. The number of walking days was categorized as $\leq 2$ times/week, 3-4 times/week, and $\geq 5$ times/week. We obtained data on body mass index $\left(\mathrm{BMI}, \mathrm{kg} / \mathrm{m}^{2}\right)$ and arterial blood pressure from health examination surveys. As obesity was considered a variable that could affect knee osteoarthritis, we defined

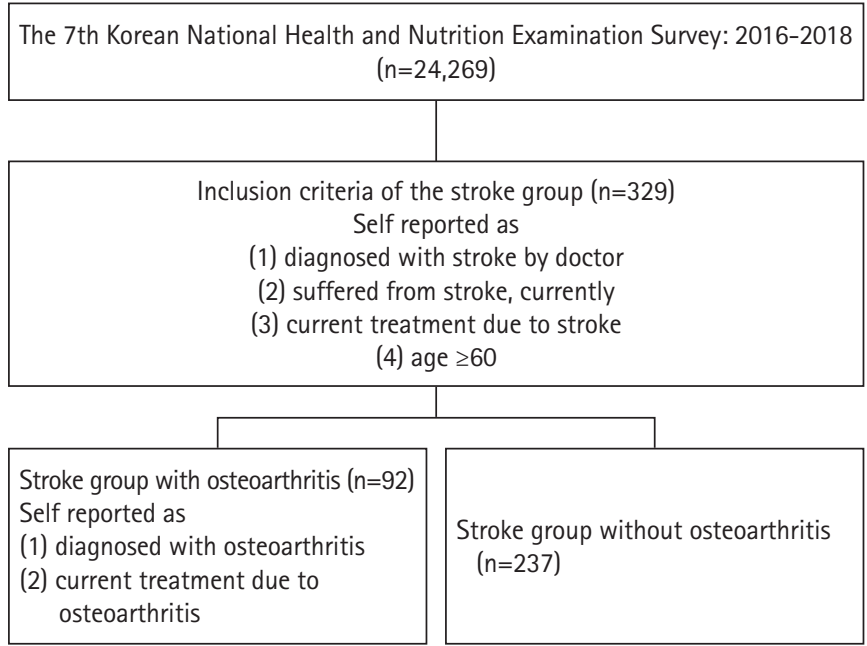

Fig. 1. Study flowchart. 
BMI values of $<25 \mathrm{~kg} / \mathrm{m}^{2}$ as normal and $\geq 25 \mathrm{~kg} / \mathrm{m}^{2}$ as obese. Hypertension was defined as a systolic blood pressure $\geq 140$ $\mathrm{mmHg}$, diastolic blood pressure of $\geq 90 \mathrm{mmHg}$, or use of antihypertensive agents.

We defined the presence of diabetes as participants who responded that they had been diagnosed with diabetes, were currently experiencing diabetes, or were currently undergoing diabetes treatment. We defined the presence of cardiovascular disease (myocardial infarction or angina pectoris) as participants who responded that they had been diagnosed with cardiovascular disease, were currently experiencing the disease, or were currently undergoing treatment for the disease.

\section{Statistical Analysis}

The sampling in the KNHANES follows a multi-stage clustered probability design, which is a complex sample design method to improve sample representativeness and estimation accuracy. Therefore, this study reflected the weight, strata, and cluster variables for accurate data analysis, and we performed all statistical analyses using the complex sample data analysis method. All missing values were reflected without omission to avoid bias in the variance (standard error [SE]) of the estimate.

Chi-squared tests were performed to compare the proportions of categorical variables, and independent t-tests were performed to compare differences in continuous variables between participants in the stroke group with and without knee osteoarthritis.

The prevalence of knee osteoarthritis in the stroke group was estimated using complex sample logistic analysis adjusted for age. Univariate logistic regression and age- and sex-adjusted multivariate logistic regression analyses were used to identify factors significantly related to knee osteoarthritis in the stroke group. To compare the differences in HRQOL according to the presence or absence of knee osteoarthritis in the stroke group, we calculated the adjusted means of each dimension of the EQ-5D and EQ-5D index after adjusting for age and sex. The mean scores of each domain of EQ-5D between intergroups were compared using t-tests.

To identify the significance of sociodemographic factors (sex, age, income, education), lifestyle factors (obesity, weekly alcohol intake, smoking status, number of weekly walking days), and comorbidities (hypertension, diabetes, cardiovascular disease) on HRQOL in the stroke group, a simple linear regression analysis was performed. Variables with p-values $<0.05$ in the simple linear regression analysis were included in the multiple linear regression analysis. All data analyses were performed using Statistical Analysis System (SAS) version 9.4 (SAS Institute Inc., Cary, NC, USA), with $\mathrm{p}$-values $<0.05$ indicating statistical significance.

\section{RESULTS}

Distributions of Characteristics according to Knee Osteoarthritis in the Stroke Group

Among 25,534 individuals who participated in the 5th $\mathrm{KN}$ HANES from 2010 to 2012, the stroke group included 287 individuals. Patients in the stroke group with knee osteoarthritis were older than those in the stroke group without knee osteoarthritis ( 73.7 vs. 70.0 years; $p<0.0001$ ). The prevalence of knee osteoarthritis was significantly higher in women than in men in the stroke group ( $31.7 \%$ vs. $11.7 \%)$. The prevalence of knee osteoarthritis trend tended to increase with age; it was $14.9 \%$ among participants in their 60 s, $22.1 \%$ among those in their 70 s, and $38.4 \%$ among those aged $\geq 80$ years ( $\mathrm{p}$ for trend $=0.018$ ).

We observed no significant differences in income $(p=0.288)$, obesity $(p=0.350)$, smoking status $(p=0.103)$, aerobic exercise $(\mathrm{p}=0.178)$, hypertension $(\mathrm{p}=0.119)$, diabetes $(\mathrm{p}=0.910)$, or cardiovascular disease $(\mathrm{p}=0.095)$ between the intergroups (Table 1$)$.

\section{Age-adjusted Prevalence of Knee Osteoarthritis and its Related Factors in the Stroke Group}

The prevalence of knee osteoarthritis in stroke patients aged $\geq 60$ years was $21 \%$. Even after adjusting for age, the prevalence of knee osteoarthritis tended to decrease with income $(25.3 \%, 22.1 \%$, $16.4 \%$, and $12.3 \%$ in the low, middle-low, middle-high, and high income groups, respectively) and education ( $24.2 \%$ in $\leq$ middle school and $5.5 \%$ in $\geq$ high school). The unadjusted odds ratios (ORs) for the association between knee osteoarthritis and each variable were significant for sex, age, education, and alcohol consumption 2-3 times/week. After adjusting the ORs for age and sex, only education ( $\geq$ high school: adjusted OR $=0.304 ; 95 \%$ confidence interval $[\mathrm{CI}], 0.113-0.818)$ was a significantly related factor (Table 2).

\section{Differences in HRQOL according to Knee Osteoarthritis Status in the Stroke Group after Adjusting for Age and Sex}

The average score for each dimension was significantly higher in the knee osteoarthritis group, indicating a poor HRQOL $(\mathrm{p}<0.001)$. The EQ-5D index was significantly lower in the knee osteoarthritis group (adjusted mean \pm SE, $0.680 \pm 0.011$ ) than in the non-knee osteoarthritis group $(0.817 \pm 0.003)(\mathrm{p}<0.0001)$ (Table 3).

\section{Factors Affecting HRQOL in the Stroke Group}

The simple linear regression models for the EQ-5D index showed significant $(p<0.05)$ associations between the presence of knee osteoarthritis and sex, age, education, alcohol intake, smoking sta- 
Table 1. Distribution of characteristics of knee osteoarthritis in the stroke group

\begin{tabular}{|c|c|c|c|}
\hline \multirow{2}{*}{ Variable } & \multicolumn{2}{|c|}{ Knee osteoarthritis } & \multirow{2}{*}{$\mathrm{p}$-value } \\
\hline & No $(n=222)$ & Yes $(n=65)$ & \\
\hline Sex & & & 0.001 \\
\hline Male & $136(88.3)$ & $19(11.7)$ & \\
\hline Female & $86(68.3)$ & $46(31.7)$ & \\
\hline Age (y) & $70.0 \pm 0.5$ & $73.7 \pm 0.8$ & $<0.0001$ \\
\hline Age group (y) & & & 0.018 \\
\hline $60-69$ & $110(85.1)$ & $23(14.9)$ & \\
\hline $70-79$ & $94(77.9)$ & $29(22.1)$ & \\
\hline$\geq 80$ & $18(61.6)$ & $13(38.4)$ & \\
\hline Income & & & 0.288 \\
\hline Low & $64(74.3)$ & $22(25.7)$ & \\
\hline Middle-low & $41(73.5)$ & $18(26.5)$ & \\
\hline Middle-high & $61(82.7)$ & $18(17.3)$ & \\
\hline High & $54(86.2)$ & $7(13.8)$ & \\
\hline Education & & & $<0.0001$ \\
\hline$\leq$ Middle school & $147(73.7)$ & $59(26.3)$ & \\
\hline$\geq$ High school & $73(94.4)$ & $6(5.6)$ & \\
\hline Obesity & & & 0.350 \\
\hline No & $35(84.0)$ & $7(16.0)$ & \\
\hline Yes & $174(77.0)$ & $58(23.0)$ & \\
\hline Alcohol intake per week & & & 0.041 \\
\hline No drinking & $108(73.0)$ & $43(27.0)$ & \\
\hline$\leq 1$ & $70(85.0)$ & $15(15.0)$ & \\
\hline $2-3$ & $22(95.7)$ & $1(4.3)$ & \\
\hline$\geq 4$ & $20(81.0)$ & $5(19.0)$ & \\
\hline Smoking status & & & 0.103 \\
\hline No & $180(77.2)$ & $84(22.8)$ & \\
\hline Yes & $39(89.0)$ & $8(11.0)$ & \\
\hline Walking days per week & & & 0.178 \\
\hline$\leq 2$ & $85(75.6)$ & $29(24.4)$ & \\
\hline $3-4$ & $37(90.2)$ & $5(9.8)$ & \\
\hline$\geq 5$ & $97(78.6)$ & $30(21.4)$ & \\
\hline Hypertension & & & 0.119 \\
\hline No & $46(87.3)$ & $7(12.7)$ & \\
\hline Yes & $174(77.0)$ & $58(23.0)$ & \\
\hline Diabetes & & & 0.910 \\
\hline No & $130(79.8)$ & $35(20.2)$ & \\
\hline Yes & $63(80.5)$ & $19(19.5)$ & \\
\hline Cardiovascular disease & & & 0.095 \\
\hline No & $197(77.8)$ & $60(22.2)$ & \\
\hline Yes & $25(89.1)$ & $5(10.9)$ & \\
\hline
\end{tabular}

Values are presented as number $(\%)$ or mean \pm standard error.

tus, number of walking days ( $3-4 /$ week, $\mathrm{p}=0.008$; $\geq 5$ /week, $\mathrm{p}=0.001)$, and presence of diabetes and cardiovascular disease (Supplementary Table S1).

Multiple linear regression models for the EQ-5D index indicated that knee osteoarthritis $(\mathrm{F}=99.59, \mathrm{p}<0.0001)$, age $(\mathrm{F}=19.25$, $\mathrm{p}<0.0001)$, income $(\mathrm{F}=64.34, \mathrm{p}<0.0001)$, education $(\mathrm{F}=43.18$, $\mathrm{p}<0.0001)$, weekly alcohol intake $(\mathrm{F}=84.31, \mathrm{p}<0.0001)$, smoking $(\mathrm{F}=18.43, \mathrm{p}<0.0001)$, aerobic exercise $(\mathrm{F}=68.91, \mathrm{p}<0.0001)$, diabetes $(\mathrm{F}=8.81, \mathrm{p}=0.003)$, and cardiovascular disease $(\mathrm{F}=6.45$, $\mathrm{p}=0.012$ ) were significantly associated with HRQOL in the stroke group $(\mathrm{F}=96.1, \mathrm{p}<0.0001)$ among variables with $\mathrm{p}$-values $<0.05$ in the simple linear regression analysis. Among those variables, the presence of osteoarthritis (estimate $\mathrm{B}=-0.145 ; 95 \% \mathrm{CI},-0.173$ to $-0.116)$, age $(\mathrm{B}=-0.004 ; 95 \% \mathrm{CI},-0.006$ to -0.002$)$, middle-high income ( $\mathrm{B}=-0.017 ; 95 \% \mathrm{CI},-0.034$ to 0.000$)$, alcohol consumption 2-3 times/week of ( $\mathrm{B}=-0.088 ; 95 \% \mathrm{CI},-0.109$ to -0.067$)$, walking $3-4$ days/week ( $\mathrm{B}=-0.066 ; 95 \% \mathrm{CI},-0.089$ to -0.043$)$, smoking $(\mathrm{B}=-0.066 ; 95 \% \mathrm{CI},-0.096$ to -0.035$)$, diabetes $(\mathrm{B}=-$ $0.029 ; 95 \% \mathrm{CI},-0.048$ to -0.010$)$, and cardiovascular disease $(\mathrm{B}=-0.023 ; 95 \% \mathrm{CI},-0.040$ to -0.005$)$ were associated with reduced EQ-5D index scores. High education level ( $\mathrm{B}=0.064 ; 95 \%$ CI, 0.045 to 0.083 ), middle-low income ( $\mathrm{B}=0.042 ; 95 \% \mathrm{CI}, 0.025$ to 0.059$)$, high income ( $\mathrm{B}=0.080 ; 95 \% \mathrm{CI}, 0.052$ to 0.108$)$, and walking $\geq 5$ days/week $(\mathrm{B}=0.026$; $95 \% \mathrm{CI}, 0.005$ to 0.047$)$ were the factors positively affecting HRQOL. (Table 4 ).

\section{DISCUSSION}

This cross-sectional study aimed to identify the overall prevalence of knee osteoarthritis in patients with stroke aged over 60 years and assess factors related to HRQOL in this group. This comprehensive study assessed the prevalence of osteoarthritis and HRQOL in patients with stroke aged over 60 years. Our results will help improve the HRQOL and health management of the anticipated increasing numbers of older adult stroke survivors.

First, the prevalence of osteoarthritis in patients in the stroke group aged over 60 years was $21 \%$ and was higher in women than in men. Osteoarthritis in patients with stroke may be accelerated owing to biomechanical problems such as paralysis, spasticity, sensory loss, and movement disorders. ${ }^{23,24)}$ However, the comparison of the prevalence of knee osteoarthritis between the stroke and nostroke groups of patients aged over 60 years showed no significant difference in our study (Supplementary Table S2). This is probably because this study included only patients aged over 60 years; thus, their knee osteoarthritis was likely because of aging or previous injuries. Additional research in an expanded age range of study subjects is needed. In addition, the prevalence of osteoarthritis was higher in women, those in the low-income group, and those in the low-educational level group. The high prevalence of osteoarthritis in women has been previously reported. ${ }^{25,26)}$ Women are anatomically different from men, with narrower femurs, thinner patellae, 
Table 2. Prevalence of knee osteoarthritis and its related factors in the stroke group

\begin{tabular}{|c|c|c|c|}
\hline Variable & Knee osteoarthritis $(\%)^{a)}$ & $\mathrm{uOR}(95 \% \mathrm{CI})$ & $\mathrm{aOR}^{\mathrm{b})}(95 \% \mathrm{CI})$ \\
\hline Total & 21.0 & - & - \\
\hline \multicolumn{4}{|l|}{ Sex } \\
\hline Female & 30.1 & $3.491(1.717-7.100)$ & - \\
\hline Age (y) & - & $1.103(1.049-1.161)$ & - \\
\hline \multicolumn{4}{|l|}{ Age group (y) } \\
\hline $70-79$ & 37.2 & $1.621(0.764-3.437)$ & - \\
\hline$\geq 80$ & 14.9 & $3.574(1.401-9.112)$ & - \\
\hline \multicolumn{4}{|l|}{ Income } \\
\hline Low & 24.3 & Reference & Reference \\
\hline Middle-low & 22.4 & $1.046(0.438-2.496)$ & $0.822(0.331-2.041)$ \\
\hline$\leq$ Middle school & 22.6 & Reference & Reference \\
\hline$\geq$ High school & 8.1 & $0.167(0.066-0.424)$ & $0.304(0.113-0.818)$ \\
\hline \multicolumn{4}{|l|}{ Obesity } \\
\hline No & 20.6 & Reference & Reference \\
\hline Yes & 19.7 & $1.569(0.606-4.063)$ & $0.946(0.359-2.496)$ \\
\hline \multicolumn{4}{|c|}{ Alcohol intake per week } \\
\hline No drinking & 21.6 & Reference & Reference \\
\hline$\leq 1$ & 17.3 & $0.478(0.220-1.036)$ & $0.844(0.372-1.914)$ \\
\hline $2-3$ & 6.5 & $0.121(0.015-0.966)$ & $0.276(0.035-2.172)$ \\
\hline$\geq 4$ & 22.9 & $0.634(0.200-2.010)$ & $1.192(0.352-4.039)$ \\
\hline$\geq 5$ & 22.4 & $0.841(0.426-1.662)$ & $1.295(0.615-2.724)$ \\
\hline \multicolumn{4}{|l|}{ Hypertension } \\
\hline No & 14.6 & Reference & Reference \\
\hline Yes & 20.7 & $2.052(0.816-5.165)$ & $1.391(0.533-3.634)$ \\
\hline \multicolumn{4}{|l|}{ Diabetes } \\
\hline No & 19.2 & Reference & Reference \\
\hline Yes & 17.0 & $0.960(0.477-1.933)$ & $0.788(0.354-1.757)$ \\
\hline \multicolumn{4}{|l|}{ Cardiovascular disease } \\
\hline No & 20.9 & Reference & Reference \\
\hline Yes & 9.2 & $0.429(0.152-1.211)$ & $0.359(0.119-1.076)$ \\
\hline
\end{tabular}

$\mathrm{uOR}$, unadjusted odds ratio; aOR, adjusted odds ratio; $\mathrm{CI}$, confidence interval.

${ }^{\text {a) }}$ Adjusted for age, ${ }^{\text {b) }}$ adjusted for age and sex.

larger quadriceps angle, and differences in the tibia condyle size. Moreover, differences in knee cartilage volume may play a major role, in addition to hormones. ${ }^{26-29)}$ The higher rates of osteoarthritis in the low-income and low-educated groups is consistent with findings of previous studies reporting a higher osteoarthritis burden for individuals with poor socioeconomic status. ${ }^{30,31)}$ People with lower socioeconomic status are more likely to perform knee-stressing work than office work; thus, the prevalence of os- 
Table 3. Health-related quality of life according to knee osteoarthritis status in the stroke group

\begin{tabular}{lccrr}
\hline \multirow{2}{*}{ Variable } & \multicolumn{2}{c}{ Knee osteoarthritis $^{\mathrm{a})}$} & $\mathrm{t}$ & $\mathrm{p}$-value \\
\cline { 2 - 5 } EQ-5D index score & No & Yes & -10.83 & $<0.0001$ \\
Mobility & $0.817 \pm 0.003$ & $0.680 \pm 0.011$ & 7.51 & $<0.0001$ \\
Self-care & $1.581 \pm 0.029$ & $1.915 \pm 0.027$ & 5.25 & $<0.0001$ \\
Usual activities & $1.305 \pm 0.029$ & $1.518 \pm 0.019$ & 3.72 & 0.0003 \\
Pain/discomfort & $1.487 \pm 0.028$ & $1.632 \pm 0.019$ & 9.19 & $<0.0001$ \\
Anxiety/depression & $1.517 \pm 0.028$ & $1.923 \pm 0.027$ & 5.87 & $<0.0001$ \\
\hline
\end{tabular}

Values are presented as adjusted mean \pm standard error.

EQ-5D, European Quality of Life-5 dimension.

${ }^{\text {a) }}$ Adjusted for age and sex, ${ }^{\text {b) }}$ using the chi-square test.

Table 4. Factors affecting the health-related quality of life in the stroke group

\begin{tabular}{|c|c|c|c|c|}
\hline \multirow{2}{*}{ Variable } & \multicolumn{4}{|c|}{ Multiple linear regression } \\
\hline & $\mathrm{B}$ & $\beta$ & SE & p-value \\
\hline (constant) & 1.103 & 0.000 & 0.068 & $<0.0001$ \\
\hline \multicolumn{5}{|l|}{ Osteoarthritis } \\
\hline No & Reference & - & - & \\
\hline Yes & -0.145 & -0.298 & 0.015 & $<0.0001$ \\
\hline \multicolumn{5}{|l|}{ Sex } \\
\hline Male & Reference & - & - & \\
\hline Female & -0.007 & -0.017 & 0.011 & 0.555 \\
\hline Age & -0.004 & -0.124 & 0.001 & $<0.0001$ \\
\hline \multicolumn{5}{|l|}{ Income } \\
\hline Low & Reference & - & - & \\
\hline Middle-low & 0.042 & 0.087 & 0.009 & $<0.0001$ \\
\hline Middle-high & -0.017 & -0.041 & 0.009 & 0.047 \\
\hline High & 0.080 & 0.166 & 0.014 & $<0.0001$ \\
\hline \multicolumn{5}{|l|}{ Education } \\
\hline$\leq$ Middle school & Reference & - & - & \\
\hline$\geq$ High school & 0.064 & 0.148 & 0.010 & $<0.0001$ \\
\hline \multicolumn{5}{|c|}{ Alcohol intake per week } \\
\hline No drinking & Reference & - & - & \\
\hline$\leq 1$ & 0.0001 & 0.0002 & 0.012 & 0.993 \\
\hline $2-3$ & -0.088 & -0.138 & 0.011 & $<0.0001$ \\
\hline$\geq 4$ & 0.011 & 0.017 & 0.008 & 0.172 \\
\hline \multicolumn{5}{|l|}{ Smoking status } \\
\hline No & Reference & - & - & \\
\hline Yes & -0.066 & -0.122 & 0.015 & $<0.0001$ \\
\hline \multicolumn{5}{|l|}{ Walking days per week } \\
\hline$\leq 2$ & Reference & - & - & \\
\hline $3-4$ & -0.066 & -0.124 & 0.015 & $<0.0001$ \\
\hline$\geq 5$ & 0.026 & 0.068 & 0.011 & 0.014 \\
\hline \multicolumn{5}{|l|}{ Diabetes } \\
\hline No & Reference & - & - & \\
\hline Yes & -0.029 & -0.071 & 0.010 & 0.003 \\
\hline \multicolumn{5}{|l|}{ Cardiovascular disease } \\
\hline No & Reference & - & - & \\
\hline Yes & -0.023 & -0.033 & 0.009 & 0.012 \\
\hline
\end{tabular}

B, estimate; $\beta$, standardized estimate; SE, standard error. 
teoarthritis is higher in this population The age- and sex-adjusted ORs of knee osteoarthritis in this study showed that the lower the education level, the higher the risk of knee osteoarthritis. Therefore, it is important to educate stroke survivors who are women or with low levels of education and income on proper exercise and lifestyle habits to prevent osteoarthritis in these populations.

Second, we found that the presence of osteoarthritis negatively affected HRQOL in the stroke group. All five dimensions (mobility, self-care, usual activities, pain/discomfort, and anxiety/depression) and the EQ-5D index showed significantly worse HRQOL in the stroke group with knee osteoarthritis. Knee osteoarthritis in stroke patients was associated with an increased length of hospitalization and was related to the degree of patient daily activities. ${ }^{32)}$ Gait issues in patients with stroke were significantly related to knee pain at rest; moreover, knee osteoarthritis is also closely related to functional recovery after stroke onset. ${ }^{33,34)}$ Our findings indicated that knee osteoarthritis contributed to functional limitation and could worsen HRQOL in the stroke group, suggesting that rapid screening tests for osteoarthritis in patients with stroke and prompt management of knee osteoarthritis in these patients can improve their quality of life.

Finally, in addition to osteoarthritis, age, middle-high income, low education level, smoking, alcohol intake 2-3 times/week, diabetes, and cardiovascular disease were negatively related to HRQOL in the stroke group. After a stroke, nerves are damaged and the muscle structure changes to fast-contractile fibers, resulting in a rapid decline in muscle mass. In addition, sarcopenia caused by aging further reduces muscle strength, limiting the activities of daily life and resulting in decreased HRQOL. ${ }^{35-39)}$ In addition, social interaction decreases and psychological conditions such as depression worsen with age, which further adversely affects HRQOL. ${ }^{19)}$ Among the factors examined in this study, the controllable factors were smoking, alcohol intake, and walking. Although there were positive and negative effects depending on the subgroup of each item, when combined with other studies to date, smoking cessation and aerobic exercise such as walking positively affect HRQOL. ${ }^{40-43)}$ Regular physical activity improves functional health and energy balance; reduces the risks of cardiovascular disease, stroke, and diabetes; and is a major factor in preventing sarcopenia. ${ }^{41,43)}$ Therefore, walking and smoking cessation are expected to play important roles in the management of diabetes and cardiovascular disease, which are risk factors for HRQOL among stroke patients.

This study had several limitations. First, this was a retrospective cross-sectional study that included a survey; thus, we could not identify the sequential or causal relationships between stroke and osteoarthritis. Second, although we conducted a secondary analy- sis of the KNHANES data, the final analysis included 287 samples, which is less than the total number of stroke patients in Korea. Third, we did not perform detailed classifications and analyses according to lesions as well as osteoarthritis and stroke severities. Future research considering the severity and characteristics of stroke and knee osteoarthritis is needed.

The study results confirmed that the prevalence of knee osteoarthritis was $21 \%$ among patients with stroke aged over 60 years and that HRQOL was significantly lower in the group of patients with stroke and knee osteoarthritis than in the group of patients with stroke and without knee osteoarthritis. Therefore, improving the quality of life of stroke survivors requires active management of knee osteoarthritis, including appropriate medical approaches such as preventive exercise, pain control, physical therapy, and rehabilitation considered to be helpful in daily life.

\section{SUPPLEMENTARY MATERIALS}

Supplementary materials can be found via https://doi.org/10.4235/ agmr.21.0053.

\section{ACKNOWLEDGMENTS}

We express our appreciation to team of Biostatistics in Ajou Research Institute for Innovative Medicine.

This work has been shared via the preprint server (http://doi. org/10.21203/rs.3.rs-37188/v1)

\section{CONFLICT OF INTEREST}

The researchers claim no conflicts of interest.

\section{FUNDING}

None.

\section{AUTHOR CONTRIBUTIONS}

Conceptualization, HJL; Data curation, HJL; Investigation, KYJ, HJL; Methodology, HJL; Project administration, KYJ, HJL; Supervision, HJL; Writing-original draft, JKY, HJL; Writing-review \& editing, KYJ, HJL.

\section{REFERENCES}

1. Donkor ES. Stroke in the 21st century: a snapshot of the burden, epidemiology, and quality of life. Stroke Res Treat 2018;2018: 3238165 .

2. Yoon $\mathrm{H}$. Factors affecting quality of life of the Korean aged stroke patients. Int J Aging Hum Dev 1997;44:167-81. 
3. Kwon S, Park JH, Kim WS, Han K, Lee Y, Paik NJ. Health-related quality of life and related factors in stroke survivors: data from Korea National Health and Nutrition Examination Survey (KNHANES) 2008 to 2014. PLoS One 2018; 13:e0195713.

4. Shan L, Shan J, Saxena A, Robinson D. Quality of life and functional status after carotid revascularisation: a systematic review and meta-analysis. Eur J Vasc Endovasc Surg 2015;49:634-45.

5. Kim JY, Kang K, Kang J, Koo J, Kim DH, Kim BJ, et al. Executive summary of stroke statistics in Korea 2018: a report from the Epidemiology Research Council of the Korean Stroke Society. J Stroke 2019;21:42-59.

6. Hong KS, Bang OY, Kang DW, Yu KH, Bae HJ, Lee JS, et al. Stroke statistics in Korea. Part I. Epidemiology and risk factors: a report from the Korean Stroke Society and Clinical Research Center for Stroke.J Stroke 2013;15:2-20.

7. Gresham GE, Phillips TF, Wolf PA, McNamara PM, Kannel WB, Dawber TR. Epidemiologic profile of long-term stroke disability: the Framingham study. Arch Phys Med Rehabil 1979; 60:487-91.

8. Adamson J, Beswick A, Ebrahim S. Is stroke the most common cause of disability? J Stroke Cerebrovasc Dis 2004;13:171-7.

9. McLean DE. Medical complications experienced by a cohort of stroke survivors during inpatient, tertiary-level stroke rehabilitation. Arch Phys Med Rehabil 2004;85:466-9.

10. Edgley SR, Gershkoff AM. Common pain syndromes in stroke patients: review of two cases. Top Stroke Rehabil 2010;17:17982.

11. Jacob L, Tanislav C, Kostev K. Osteoarthritis and incidence of stroke and transient ischemic attack in 320,136 adults followed in general practices in the United Kingdom. Joint Bone Spine 2021;88:105104.

12. Lee HS. Prevalence of osteoarthritis and related risk factors in the elderly: data from the fifth Korea National Health and Nutrition Examination Survey (KNHANES V), 2010-2012. J Korean Diet Assoc 2014;20:99-109.

13. Swain S, Sarmanova A, Coupland C, Doherty M, Zhang W. Comorbidities in osteoarthritis: a systematic review and meta-analysis of observational studies. Arthritis Care Res (Hoboken) 2020;72:991-1000.

14. Jung JH, Seok H, Kim JH, Song GG, Choi SJ. Association between osteoarthritis and mental health in a Korean population: a nationwide study. Int J Rheum Dis 2018;21:611-9.

15. Kaufman KR, Hughes C, Morrey BF, Morrey M, An KN. Gait characteristics of patients with knee osteoarthritis. J Biomech 2001;34:907-15.

16. Valderrabano V, Nigg BM, von Tscharner V, Stefanyshyn DJ, Goepfert B, Hintermann B. Gait analysis in ankle osteoarthritis and total ankle replacement. Clin Biomech (Bristol, Avon) 2007; 22:894-904.

17. Parker L, Moran GM, Roberts LM, Calvert M, McCahon D. The burden of common chronic disease on health-related quality of life in an elderly community-dwelling population in the UK. Fam Pract 2014;31:557-63.

18. Ostwald SK, Wasserman J, Davis S. Medications, comorbidities, and medical complications in stroke survivors: the CAReS study. Rehabil Nurs 2006;31:10-4.

19. Sivertsen H, Bjorklof GH, Engedal K, Selbæk G, Helvik AS. Depression and quality of life in older persons: a review. Dement Geriatr Cogn Disord 2015;40:311-39.

20. Min S. Aging vulnerability index of Korea. Korean J Econ 2012;19:49-80.

21. Nam HS, Kim KY, Kwon SS, Koh KW, Paul K. Research report for estimated weight for quality of life survey (EQ-5D). Cheongju, Korea: Korea Centers for Disease Control and Prevention; 2007.

22. Oh HS. Important significant factors of health-related quality of life (EQ-5D) by age group in Korea based on KNHANES (2014).J Korean Data Inf Sci Soc 2017;28:573-84.

23. Kendall R. Musculoskeletal problems in stroke survivors. Top Stroke Rehabil 2010;17:173-8.

24. Kim KT, Chung ME. Musculoskeletal problems in lower extremity after stroke. Brain Neurorehabil 2016;9:13-9.

25. Cho HJ, Chang CB, Kim KW, Park JH, Yoo JH, Koh IJ, et al. Gender and prevalence of knee osteoarthritis types in elderly Koreans. J Arthroplasty 2011;26:994-9.

26. Hame SL, Alexander RA. Knee osteoarthritis in women. Curr Rev Musculoskelet Med 2013;6:182-7.

27. Conley S, Rosenberg A, Crowninshield R. The female knee: anatomic variations. J Am Acad Orthop Surg 2007;15 Suppl 1:S31-6.

28. Ding C, Cicuttini F, Blizzard L, Scott F, Jones G. A longitudinal study of the effect of sex and age on rate of change in knee cartilage volume in adults. Rheumatology (Oxford) 2007;46:273-9.

29. Wluka AE, Davis SR, Bailey M, Stuckey SL, Cicuttini FM. Users of oestrogen replacement therapy have more knee cartilage than non-users. Ann Rheum Dis 2001;60:332-6.

30. Gustafsson K, Kvist J, Eriksson M, Dahlberg LE, Rolfson O. Socioeconomic status of patients in a Swedish national self-management program for osteoarthritis compared with the general population-a descriptive observational study. BMC Musculoskelet Disord 2020;21:10.

31. Thumboo J, Chew LH, Lewin-Koh SC. Socioeconomic and psychosocial factors influence pain or physical function in Asian patients with knee or hip osteoarthritis. Ann Rheum Dis 2002; 61:1017-20.

32. Nguyen-Oghalai TU, Ottenbacher KJ, Granger CV, Goodwin JS. 
Impact of osteoarthritis on the rehabilitation of patients following a stroke. Arthritis Rheum 2005;53:383-7.

33. Doruk P. The impact of knee osteoarthritis on rehabilitation outcomes in hemiparetic stroke patients. J Back Musculoskelet Rehabil 2013;26:207-11.

34. Jeong H, Baek SY, Kim SW, Eun YH, Kim IY, Lee J, et al. Comorbidities and health-related quality of life in Koreans with knee osteoarthritis: data from the Korean National Health and Nutrition Examination Survey (KNHANES). PLoS One 2017;12: e0186141.

35. Scherbakov N, von Haehling S, Anker SD, Dirnagl U, Doehner W. Stroke induced sarcopenia: muscle wasting and disability after stroke. Int J Cardiol 2013;170:89-94.

36. Su Y, Yuki M, Otsuki M. Prevalence of stroke-related sarcopenia: a systematic review and meta-analysis. J Stroke Cerebrovasc Dis 2020;29:105092.

37. Li W, Yue T, Liu Y. New understanding of the pathogenesis and treatment of stroke-related sarcopenia. Biomed Pharmacother 2020;131:110721.

38. Tsekoura M, Kastrinis A, Katsoulaki M, Billis E, Gliatis J. Sarco- penia and its impact on quality of life. Adv Exp Med Biol 2017; 987:213-8.

39. Dzhus M, Dzhus M, Masnyi M, Kulyk M, Mostbauer H, Ivashkivsky O, et al. Cross-sectional Evaluation of the Sarcopenia Quality of Life (SarQoL) questionnaire: translation and validation of its psychometric properties. Ann Geriatr Med Res 2020; 24:139-47.

40. Karmisholt K, Gøtzsche PC. Physical activity for secondary prevention of disease: systematic reviews of randomised clinical trials. Dan Med Bull 2005;52:90-4.

41. Marzetti E, Calvani R, Tosato M, Cesari M, Di Bari M, Cherubini A, et al. Physical activity and exercise as countermeasures to physical frailty and sarcopenia. Aging Clin Exp Res 2017;29:3542.

42. Chen MD, Rimmer JH. Effects of exercise on quality of life in stroke survivors: a meta-analysis. Stroke 2011;42:832-7.

43. Hays JT, Croghan IT, Baker CL, Cappelleri JC, Bushmakin AG. Changes in health-related quality of life with smoking cessation treatment. Eur J Public Health 2012;22:224-9. 